\title{
Studies on Mechanical, Electrical and Thermal Properties of ABS - PLA Blend Using Glycerol as Compatibilizer
}

\author{
G. Manoj Kumar, P.Vijaya Kumar S.Soundararajan \\ Dept Of Plastics Technology, Central Institute Of Plastics Engineering \& Technology, Guindy, Chennai, India
}

\begin{abstract}
Now a day's plastic places a vital role in the field of automotives, which needs a good impact property at a reasonable cost. ABS and PLA materials has been mixed in an appropriate proportion of 90:10, 80:20, $70: 30$ (wt\%) and a suitable compatibilizer i.e. glycerol, is also incorporated in to that mixture at a percentage of $2 \%$. Then prepared the blend by melt blending using twin-screw extruder. After blending compatibility was investigated by DSC. The ABS-PLA blended materials were tested to find the mechanical, thermal and electrical properties. The disadvantage of PLA is low impact strength and low heat deflection temperature. The main advantage of ABS is good impact strength and HDT. On blending this ABS with PLA material, good impact strength and also good thermal properties can be obtained for PLA. It can be mainly useful in the fields of automotive, electrical \& electronic housings.
\end{abstract}

Keywords: ABS, PLA, Glycerol, Melt Blending, Mechanical \& Electrical Properties, DSC.

\section{Introduction}

Polymer blends are physical mixtures of two or more polymers with/without any chemical bonding between them. The objective of polymer blending is a practical one of achieving commercially viable product through either unique properties or lower cost than some other means might provide. The subject is vast and has been the focus of much work, both theoretical and experimental. Property of polymer blends is superior to those of individual polymers. Blending technology also provides attractive opportunities for reuse and recycling of polymer wastes.

Acrylonitrile-Butadiene- Styrene is a hard and tough thermoplastic co-polymer. It is made by the combination of acrylonitrile, butadiene and styrene. To manufacture ABS, Styrene and acrylonitrile monomers are added to poly butadiene latex and the mixture is warmed to $50^{\circ} \mathrm{C}$ to allow absorption of monomers. A water soluble initiator such as potassium per sulphate is then added to polymerize styrene and acrylonitrile. The resultant polymer will be a mixture of poly butadiene grafted with acrylonitrile \& styrene and styreneacrylonitrile copolymer. ABS is amorphous and therefore has no true melting point. The proportions can vary from 15 to $35 \%$ acrylonitrile, 5 to $30 \%$ butadiene and 40 to $60 \%$ styrene. ABS can be used between -20 and 80 ${ }^{\circ} \mathrm{C}\left(-4\right.$ and $\left.176^{\circ} \mathrm{F}\right)$ as its mechanical properties vary with temperature.

Poly Lactic acid or Poly Lactide (PLA) is a thermoplastic aliphatic polyester derived from renewable resources, such as corn starch (in the United States), tapioca roots, chips or starch (mostly in Asia), or sugarcane (in the rest of the world). In 2010, PLA was the second most important bioplastic of the world in regard to consumption volume and lot of research has been done on bio-degradable polymers based on PLA [1-5]. Polylactic acid (PLA) was first discovered in 1932 by Carothers (Du Pont) who produced a low molecular weight by heating lactic acid under vacuum. Subsequently work by Du Pont and Ethicon has focused on the manufacture of medical grade sutures, implants and controlled drug release applications. The recent advance in the fermentation of dextrose obtained from corn has led to a dramatic reduction in the cost to manufacture the lactic acid necessary to make PLA polymers. Glycerol is a simple polyol compound. It is a colourless, odourless, viscous liquid that is widely used in pharmaceutical formulations. Glycerol has three hydroxyl groups that are responsible for its solubility in water and its hygroscopic nature. It can act as compatibilizer for many Polymer alloys and blends.

ABS is a low cost Engineering Plastics that is easy to machine and fabricate. ABS is having very good impact strength. ABS is an ideal material for applications where impact resistance, strength and stiffness are required. It is widely used for machining pre-production prototypes since it has excellent dimensional stability, and it is easy to paint and glue. It has excellent aesthetic quality. It is used for support block, housings and Covers. ABS is widely used in Vehicle construction industry like fascia panels, door covers, door handles, radiator grilles, ventilation system components, heater housings, seat belt fastenings, console panels, loud speaker housings, interior trims and other uses [6].

ABS is also widely used in Electrical and Electronic applications such as Electrical Housings for meters \& starters, Radio housings, Housings for Calculators, Cell phones, remote controls etc. mostly for indoor applications. ABS is photodegradable and PLA is biodegradable. Hence ABS/PLA blends will be Photo /Bio Degradable and will be environmentally friendly. 
As far as our knowledge is concerned, glycerol is not reported as compatibilizer for ABS-PLA blends. Hence, in this present study glycerol is used as a compatibilizer and the mechanical, electrical and thermal properties were studied. The compatibility was checked By DSC.

\section{Materials And Methods}

\subsection{Materials}

Commercially available injection molding grade ABS was procured from Sabic innovative plastics, properties of which are given in Table 1(a) \& commercially available Injection molding grade PLA was procured from Harita NTI limited, Chennai. Properties of which are given in Table 1(b) and finally glycerol is procured from Diucon laboratory, Chennai. Its molecular weight is $92.09 \&$ its weight per $\mathrm{ml}$ is $1.255-1.260$ (Table 1(c)).

Table 1(a) Properties of ABS

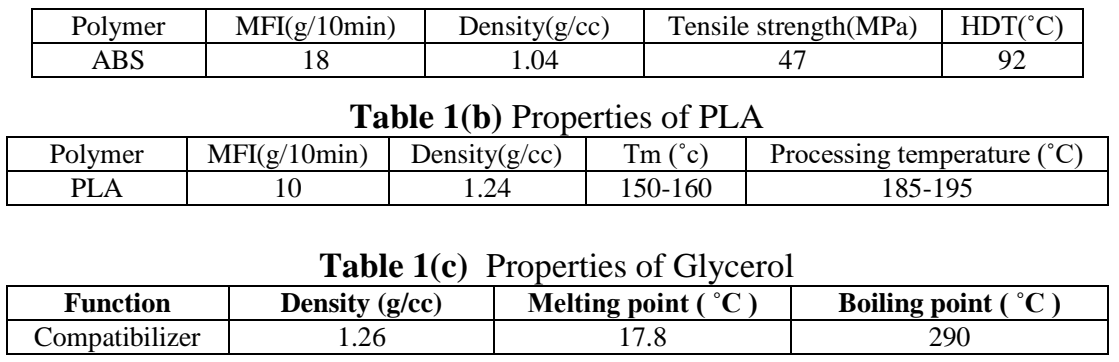

\subsection{Twin Screw Compounding (TSC)}

Before blending, the pre conditioning of the material is to be done by placing the material in an oven for not less than four hours at $80^{\circ} \mathrm{c}$. The ABS and PLA material are mixed in an appropriate ratio of 90:10\%, $80: 20 \%$ \& 70:30\% On blending these materials it becomes immiscible, so a suitable compatibilizer like glycerol is incorporated on to that three blend ratios at a percentage of $2 \%$. Plastic material in form of granules is fed into a Twin screw extruder (Bernstorff, FRG) extruder through a hopper. The material is then conveyed forward by a feeding screw and forced through a die, converting to continuous Strands The strand going out of the die is cooled in water bath and then cut into granules. The temperature range used was 120$195{ }^{\circ} \mathrm{C}$. These granules were injection molded into tensile, flexural and impact specimens and test were conducted as per ASTM standards and the properties were evaluated.

\subsection{Testing}

Test specimens were prepared by using an injection molding $\mathrm{m} / \mathrm{c}$, (SP 130 Windsor) for the mechanical, electrical and thermal properties as per ASTM standards [7]. The Tensile strength test was done using a UTM (Universal Testing Machine) Lloyd, LR 100k as per ASTM D638 Type I specimen, using 50 $\mathrm{mm} / \mathrm{min}$ test speed. The flexural strength was done as per ASTM D790, using the same UTM, with Flexure fixture. The Test speed is $2.8 \mathrm{~mm} / \mathrm{min}$. The Test specimen size $127 \times 12.7 \times 6.4 \mathrm{~mm}$. The Izod impact test is done by using Ats Faar m/c, Italy as per ASTM D256 Standards. HDT (Heat Deflection Temperature) test was carried out as per ASTM D 648 standards using a HDT machine (Ceast, Italy). The Volume and Surface resistivity Tests are carried out as per ASTM D257 Standards using 110mm dia disc with thickness 3-3.2mm with a Mho Meter (USA). The Arc resistance was carried out as per ASTM D495 standard with an arc resistance tester (Ceast, Italy). DSC was carried out using Netzsu equipments at Mogappair, Chennai.

\subsection{Mechanical Properties}

\section{Result And Discussion}

ABS and PLA material has been mixed in three different ratios with keeping $2 \%$ glycerol (compatibilizer) as constant. The test results are shown in the Table 2, 3 and 4 and in Figures 1-3. The tensile strength increases as the concentration of PLA increases, the value increases from 33.7 to $39.5 \mathrm{~N} / \mathrm{mm}^{2}$. Because PLA has higher tensile strength than ABS. But the blends have lower tensile strength than that of of Both ABS and PLA. Similarly,the flexural strength value increases when PLA concentration increases. PLA is amorphous and lower flexibility and hence the flexural strength increases. But the ABS-PLA blends have lower Flexural strength than that of ABS and PLA. The decrease in tensile and flexural strength values indicates that the PLA is not compatible with ABS in presence of Glycerol.

The impact property which plays a main role in our project, the impact property of ABS/ PLA is given in the Figure 1. The impact property decreases from 13.9 to $10.9 \mathrm{~J} / \mathrm{m}$. The impact strength of PLA is very 
lower than that of ABS. Hence the impact strength decreased as the PLA concentration was increased. Similarly the hardness increased from 79 to 81 to (Table 2).

Table 2. Tensile properties of ABS/PLA Blends

\begin{tabular}{|c|c|c|c|c|c|}
\hline S.NO & $\begin{array}{c}\text { Material } \\
(\text { ABS:PLA })\end{array}$ & $\begin{array}{c}\text { Tensile strength } \\
\left(\mathrm{N} / \mathrm{mm}^{2}\right)\end{array}$ & $\begin{array}{c}\text { Flexural Strength } \\
\left(\mathrm{N} / \mathrm{mm}^{2}\right)\end{array}$ & Impact strength, Izod, (J/m) & $\begin{array}{c}\text { Hardness } \\
\text { Shore D }\end{array}$ \\
\hline 1 & $100: 0$ & 47.0 & 65 & 29.0 & 105 \\
\hline 2 & $90: 10$ & 33.7 & 40.9 & 13.9 & 79 \\
\hline 3 & $80: 20$ & 36.9 & 43.6 & 11.8 & 80 \\
\hline 4 & $70: 30$ & 39.5 & 45.3 & 2.0 & 81 \\
\hline 5 & $0: 100$ & 53 & 74 & & 114 \\
\hline
\end{tabular}

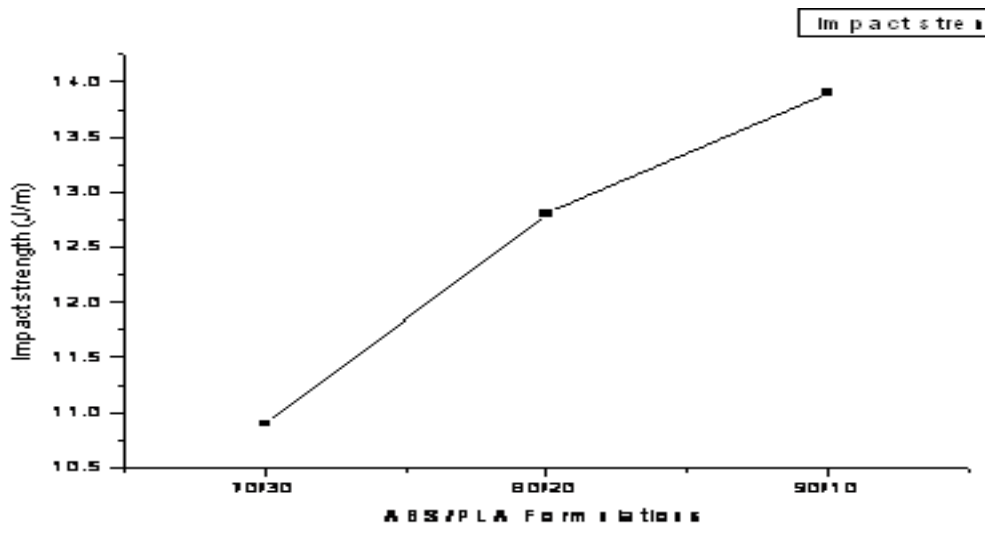

Figure 1 Impact strength of ABS/PLA Blends

\subsection{Thermal property:}

The heat deflection temperature results of ABS/PLA at a concentration of $2 \%$ glycerol is shown in fig 2; the readings of HDT increases from $71.8^{\circ} \mathrm{C}$ to $74.5^{\circ} \mathrm{C}$. The PLA has lower HDT than ABS. Hence the HDT values are decreasing as the concentration PLA increases in the ABS /PLA blends.

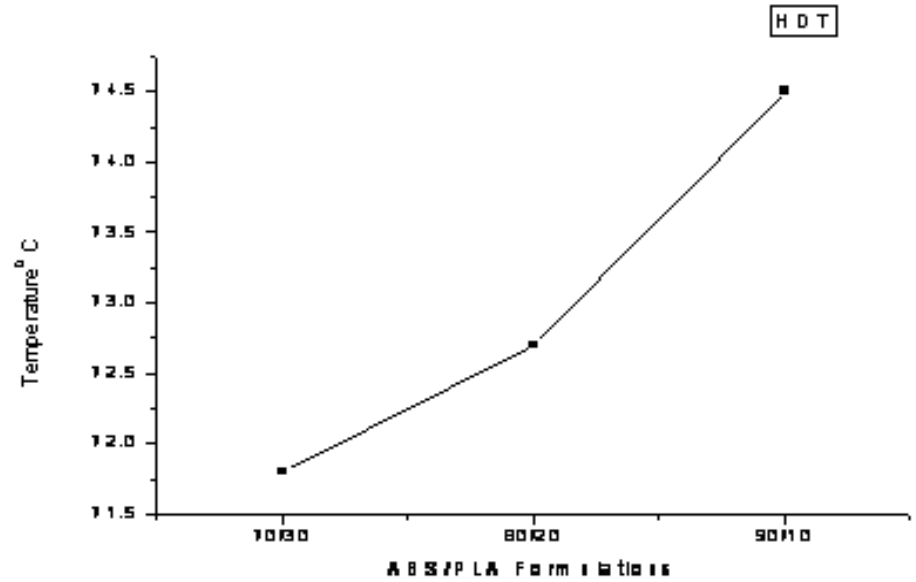

Figure 2 HDT of ABS /PLA blends

\subsection{Electrical Property}

The volume \& surface resistivity results of ABS/PLA at a concentration of $2 \%$ glycerol is given in the Table 3, the readings of Volume resistivity decreases from $4.8 \times 10^{16}$ to $2.7 \times 10^{14}$ ohms-cm \& the surface resistivity decreases from $3.9 \times 10^{14}$ to $2.7 \times 10^{12}$ ohms as concentration of PLA increases. The PLA has Optimum volume resistivity and surface resistivity. 
Table 3 Volume \& surface resistance ABS/PLA Blends

\begin{tabular}{|c|c|c|c|c|c|}
\hline S.NO & $\begin{array}{c}\text { Material } \\
\text { (ABS:PLA) }\end{array}$ & $\begin{array}{c}\text { Volume } \\
\text { resistivity } \\
(\text { ohm-cm })\end{array}$ & $\begin{array}{c}\text { Surface } \\
\text { resistivity } \\
(\text { ohms })\end{array}$ & $\begin{array}{c}\text { Dielectric strength } \\
(\mathrm{KV} / \mathrm{mm})\end{array}$ & $\begin{array}{c}\text { Arc resistance } \\
\text { ( seconds })\end{array}$ \\
\hline 1 & $90: 10$ & $4.8 \times 10^{16}$ & $3.9 \times 10^{14}$ & 16.19 & 150 \\
\hline 2 & $80: 20$ & $2.2 \times 10^{16}$ & $3.2 \times 10^{14}$ & 13.61 & 135 \\
\hline 3 & $70: 30$ & $2.7 \times 10^{14}$ & $2.7 \times 10^{12}$ & 11.67 & 190 \\
\hline 4 & $0: 100$ & $2.97 \times 10^{14}$ & $1.5 \times 10^{13}$ & 11.38 & \\
\hline
\end{tabular}

The higher the insulation resistance is, the better the insulator. As higher the temperature and humidity, the lower the insulation resistance of a material. he ABS/PLA blend has good dielectric strength.On the addition of amount of PLA the property was decreased.The Arc resistance results of ABS/PLAdecreases from 150 to126 Seconds even though PLA has higher arc resistance (190 Seconds).

\subsection{Thermal Analysis}

\subsubsection{Differential Scanning Calorimetry}

The DSC is used to find whether the given blend is miscible or immiscible. It is also used to find the glass transition temperature, melting point and degradation temperature. The following figures (3a-3c) show thermograms ABS/PLA blends. The tables $4 \mathrm{a}-4 \mathrm{c}$ that give the complete data about the ABS/PLA blends.

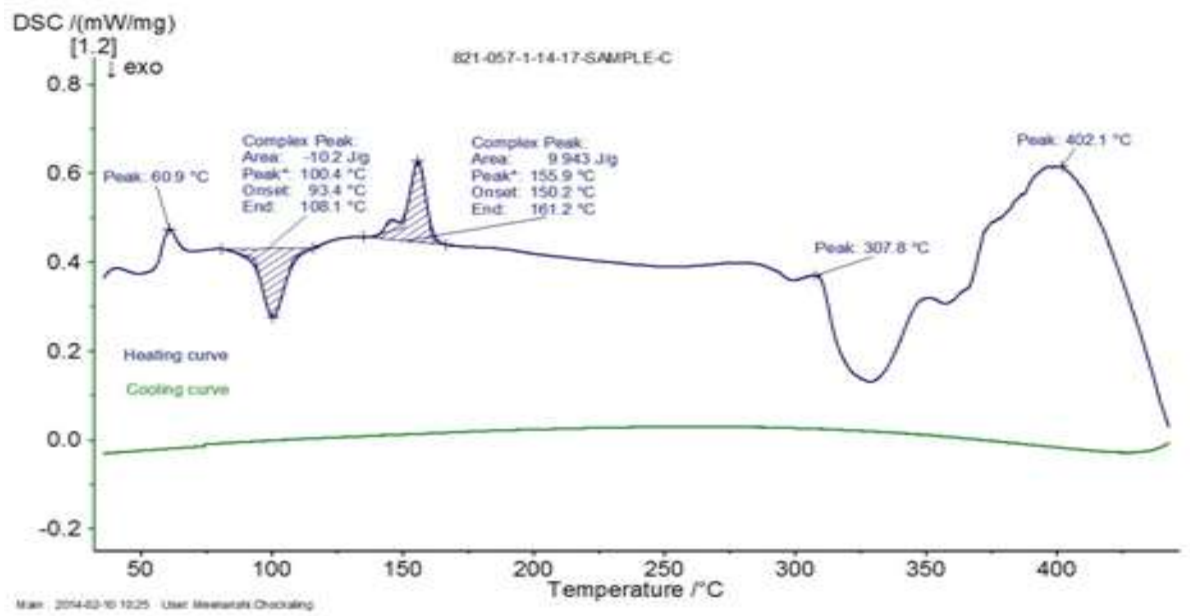

Figure 3(a) DSC Image for ABS/PLA Blend (70:30\%)

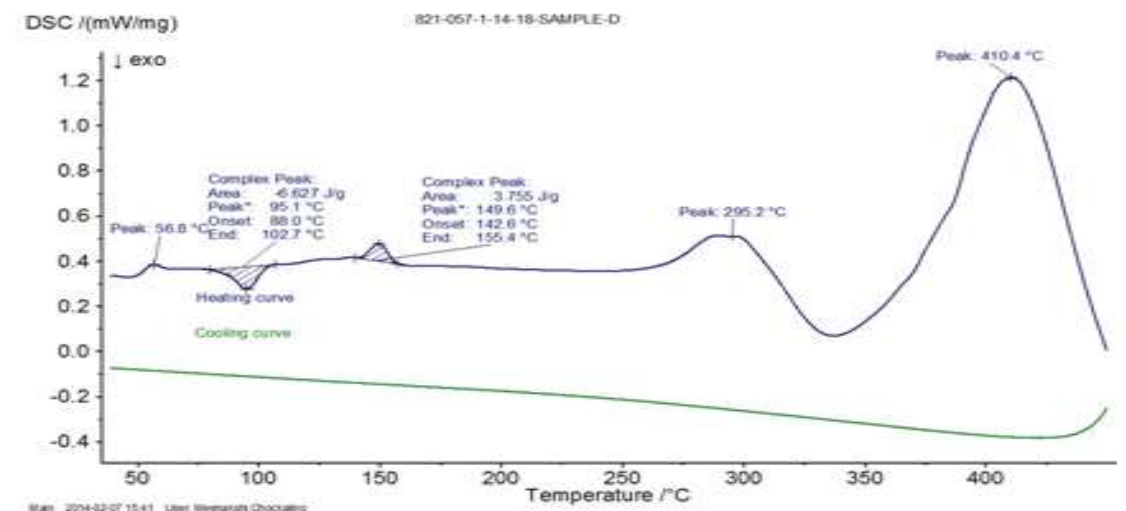

Figure 3(b): DSC Image for ABS/PLA Blend (80:20\%) 


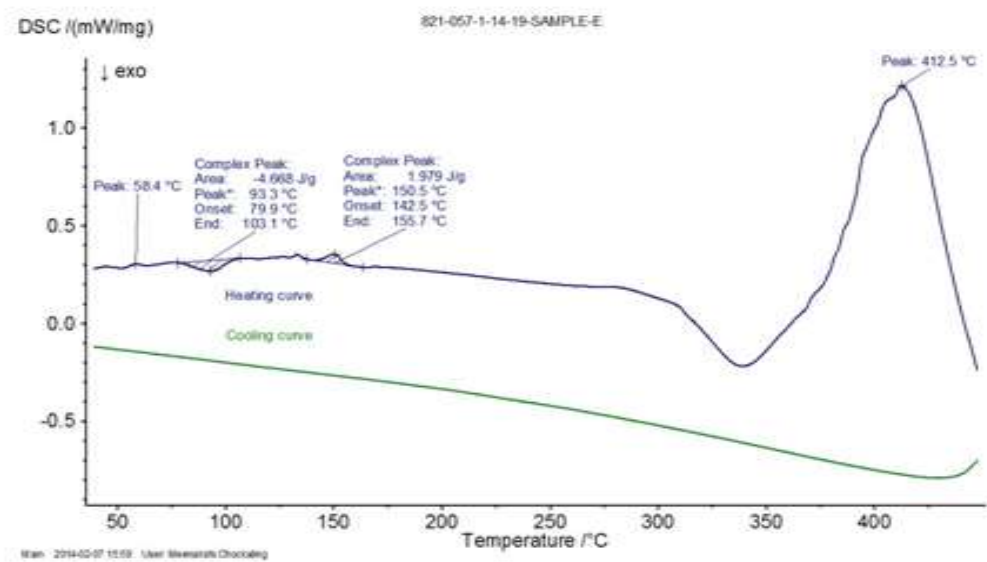

figure 3(c): Image of ABS/PLA Blend (90:10\%)

Table 4(a) DSC result of ABS/PLA Blend (90:10\%)

\begin{tabular}{|c|c|c|c|c|}
\hline S.NO & $\begin{array}{c}\text { Material } \\
\text { (ABS:PLA) } \\
(90: 10)\end{array}$ & $\begin{array}{c}\text { Glass transition } \\
\text { temperature }\left({ }^{\circ} \mathrm{C}\right)\end{array}$ & $\begin{array}{c}\text { Melting point } \\
\left({ }^{\circ} \mathrm{C}\right)\end{array}$ & $\begin{array}{c}\text { Degradation temperature } \\
\left({ }^{\circ} \mathrm{C}\right)\end{array}$ \\
\hline 1 & ABS & 93.3 & - & 412.5 \\
\hline 2 & PLA & 58.4 & 150.5 & 310.2 \\
\hline
\end{tabular}

Table 4 (b) DSC result of ABS/PLA Blend (80:20\%)

\begin{tabular}{|c|c|c|c|c|}
\hline S.NO & $\begin{array}{c}\text { Material } \\
(\text { ABS:PLA }) \\
(80: 20)\end{array}$ & $\begin{array}{c}\text { Glass transition temperature } \\
\left({ }^{\circ} \mathrm{C}\right)\end{array}$ & Melting point $\left({ }^{\circ} \mathrm{C}\right)$ & Degradation temperature $\left({ }^{\circ} \mathrm{C}\right)$ \\
\hline 1 & ABS & 95.1 & - & 410.4 \\
\hline 2 & PLA & 56.8 & 149.6 & 295.2 \\
\hline
\end{tabular}

Table 4(c) DSC result of ABS/PLA Blend (70:30\%)

\begin{tabular}{|c|c|c|c|c|}
\hline S.NO & $\begin{array}{c}\text { Material } \\
(\text { ABS:PLA }) \\
(70: 30)\end{array}$ & $\begin{array}{c}\text { Glass transition } \\
\text { temperature }\left({ }^{\circ} \mathrm{C}\right)\end{array}$ & $\begin{array}{c}\text { Melting point } \\
\left({ }^{\circ} \mathrm{C}\right)\end{array}$ & \begin{tabular}{c} 
Degradation temperature $\left({ }^{\circ} \mathrm{C}\right)$ \\
\hline 1
\end{tabular} \\
\hline ABS & 100.4 & - & 402.1 \\
\hline 2 & PLA & 60.9 & 155.9 & 307.8 \\
\hline
\end{tabular}

The Tg peaks for ABS and PLA were present individually for all compositions which shows the ABS and PLA are immisible in the presence of Glycerol. The Tg Peaks of ABS and that of PLA were shifted to lower values which reveal there is an interaction between these two Polymers. The glycerol has three hydroxyl groups which will be reacting with end $-\mathrm{OH}$ and $-\mathrm{COOH}$ groups of PLA and also reacts with Hydrogen atoms of ABS. Hence partial compatibility can be achieved. Also, uniform change in properties like Impact, HDT indicates that ABS -PLA blends may be partially compatible due to Polar nature of these two polymers. So, the Tg peaks were shifted slightly. The Td of ABS was slightly increased. The compatibility can be increased by the use of Maleic Anhydride-graft - ABS at about 5-10\% of ABS -PLA resin [8].

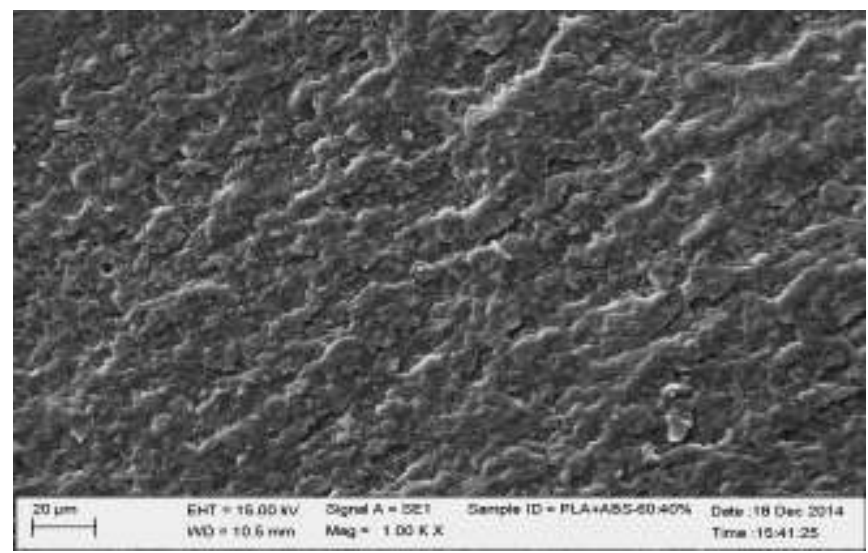

Figure 4 SEM of ABS -PLA (40:60\%) 
However, we have taken SEM for ABS-PLA (40:60\%) compatibilized with Glycerol 2\% (1000 magnification) and is shown in Figure 4 which indicates the ABS is Compatible with PLA. If more than 50\% PLA $(60 \%)$ is present in the blend, the Bio-Degradability will be more faster, But the impact strength will be lowered much. For products with better impact strength to be present the ABS\% should be more than $70 \%$ in the ABS-PLA blends.

\section{Conclusion}

As the concentration of PLA increases the impact strength decreases uniformly, since PLA has lower impact strength and HDT decreases. The PLA is a hygroscopic material. hen the concentration of PLA increases in the ABS/PLA blend the moisture absorption will increase, hence the electrical insulation decreases. So volume \& surface resistivity, dielectric strength, and arc resistance are lowered. DSC thermograms show that the Tg Peaks of ABS and that of PLA were shifted to lower values which reveal s there is an interaction between these two Polymers. Also, uniform change in properties like Impact, HDT indicates that ABS -PLA blends may be partially compatible due to polar nature of these two polymers in presence of Glycerol as compatibilizer. The tensile strength, flexural strength and hardness are lower than that of both ABS and PLA reveals that PLA is not compatible with ABS in presence of glycerol. However, SEM for ABS-PLA (40:60\%) compatibilized with Glycerol 2\% which indicates the ABS is Compatible with PLA. If more than 50\% PLA $(60 \%)$ is present in the blend, the Bio-Degradability will be more faster, but the impact strength will be lowered much. For products with better impact strength to be present the ABS\% should be more than $70 \%$ in the ABSPLA blends. ABS is photodegradable and PLA is Biodegradable, hence photo /biodegradable products can be developed from ABS /PLA blends with optimum impact strength and HDT values.

\section{References}

[1]. Esmat Jalalvandi, Rohah Abd. Majid, Taravat Ghanbari, Processing, Morphological, Thermal and Absorption Behavior of PLA/Thermoplastic Starch/Montmorillonite Nanocomposites, World Academy of Science, Engineering and Technology, 2012, 72, $12-23$.

[2]. Fei feng, Lin ye, Structure and Property of Polylactide/Polyamide Blends, Journal of Macromolecular Science,Part B Physics, 2010, 49, 1117-1127

[3]. Sebnem Kemaloglu Dogan, Serap Gumus, Guralph ozcoc, Ayse Aytac,, Properties of modified ethylene terpolymer/poly (lactic acid) blends based films, 2013, 14, 1422-1431

[4]. Shulin sun, Mingyao Zhang, Huixuan Zhang, Xiumei Zhang, Polylactide toughening with epoxy-functionalized grafted acrylonitrile-butadiene-styrene particles, 2011, 122, 2992-2999.

[5]. Yu Muhuo, Elwathig Hassan, You Wei, He Jiao, Dynamic Mechanical Properties and Thermal Stability of Poly(lactic acid) and Poly(butylene succinate) Blends Composites , Journal of fiber Bioengineering and Informatics 2013, 6, 85-94.

[6]. J. A. Brydson, Plastics Materials, Butterworth - Heinmann, $7^{\text {th }}$ edition, New Delhi, 2005, P $462-464$

[7]. Annual ASTM Standards, Vol. 08.01-03, Philadelpia, USA,

[8]. S Balakrishnan and N R Neelakantan, Polymer International, 1998, 45, 347-352 